\title{
Inhibitory Effects of Methoxyfenozide on Reproductive Organs of Cotton Leafworm, Spodoptera Littoralis (Boisd.) Hend M. Sabry ${ }^{1}$; Hala M. I. Mead ${ }^{1}$ and Karima S. Khater ${ }^{2}$ \\ ${ }^{1}$ Plant Protection Research Institute, Agricultural Research Center, Dokki, Giza, Egypt. \\ ${ }^{2}$ Faculty of Science, Zoology Department, Zagazig University, Egypt.
}

\begin{abstract}
Current research has focused on the inhibitory effects on the reproductive organs of cotton leafworm, Spodoptera littoralis resulting from $4^{\text {th }}$ instar larvae treated with sublethal concentration $\left(\mathrm{LC}_{25}\right)$ of methoxyfenozide. Results showed elongation in the immature stages and longevity of adults than control, as well as reduce pupal weight, oviposition period, fecundity and hatchability percentages. Anatomical structures of virgin moths surviving from larvae treated with $\mathrm{LC}_{25}$ of methoxyfenozide showed general atrophy and abnormal features for ovaries and testes than that of untreated ones. Histological disruptions were recorded in ovaries in vitellogenesis and post vitellogensis stages as deformation in follicular shape, clumping of the chromatin material in nurse cells and disorganization of yolk and appearance of vacuoles between yolk and chorion. While in treated testes the testicular wall disappeared and vacuoles between follicles take place. Methoxyfenozide caused alterations in the amounts of both total soluble protein and total lipids and also in the activities of acid and alkaline phosphatases and phenol oxidase in the ovaries and testes of the resulted adults as compared to control adults.
\end{abstract}

Keywords: Spodoptera littoralis; toxic; histochemical; enzymes; methoxyfenozide

\section{INTRODUCTION}

The developmental stages of insects depend on two principal hormones, juvenile hormone $(\mathrm{JH})$ and ecdysone. $\mathrm{JH}$ is regulating molting growth and metamorphosis process (Bellés, 2005). Ecdysone plays a basic role in both molting and reproduction processes of insects such as meiotic reinitiation in oocytes, ovogenesis and growth of the spermatocytes (Raikhel et al. 2005). According to the important role of hormones in regulation the developmental and physiological process of insects, specific insecticides were developed to reduce the population of insect pests called insect growth regulators (IGRs).

Methoxyfenozide is an ecdysone agonist which manifest their activity by mimicking and binding the ecdysteroid hormone and found to be potent against lepidopteran larvae (Rehan and Freed 2014). Cotton leafworm, Spodoptera littoralis (Boisd.) is a destructive polyphagous lepidopterous pest that attacks cotton, vegetables and numerous field crops all over the year. Moreover, when large numbers of $S$. littoralis larvae are present, complete crop loss is determinism (Al-Shannaf and Khedr 2013). Thus, the objectives of this study were assessed the ovicidal and histochemical actions of methoxyfenozide on the reproductive organs of either male or female adults of $S$. littoralis.

\section{MATERIALS AND METHODS}

\section{Tested IGR:}

Runner $^{(B)} 24 \%$ SC (methoxyfenozide). The rate of application $150 \mathrm{~cm}^{3} / 200 \mathrm{~L}$ water, second generation ecdysone agonist causes cessation of feeding and premature lethal molt, an agonist of 20-hydroxyecdysone a key hormone in the molting process, basic product of Dow AgroSciences Co.

2. Culture of the cotton leafworm, Spodoptera littoralis (Boisd.) rearing technique:

A laboratory (susceptible) strain of S. littoralis was reared under no insecticidal contamination, at the department of cotton leafworm, Branch of Plant Protection Research Institute at Zagazig, Sharqia Governorate, Egypt. Egg masses were reared on leaves of castor bean, Ricinus communis, L. according to El-Defrawi et al., (1964) under invariable conditions of $26 \pm 1{ }^{\circ} \mathrm{C}$ and $70 \pm 5 \%$ relative humidity $(\mathrm{RH})$.

\section{Bioassay:}

Leaf-dipping bioassay method was used to determine the sub-lethal concentration values of the tested IGR. Six series concentrations (in water) of methoxyfenozide were prepared. Castor bean leaves were dipped for ten seconds in each concentration then left to dry. The treated leaves were offered to newly molted $4^{\text {th }}$ instar larvae for $48 \mathrm{hr}$. then replaced by untreated ones for $24 \mathrm{hr}$. Mortality percentages were recorded after $72 \mathrm{hr}$. and corrected according to Abbott's formula (1925) to estimate the LC values, the corrected mortality percentages were subjected to probit analysis according to Finney (1971). For measuring biological parameters, the concentration $\mathrm{LC}_{25}$ was used against fifty newly molted $4^{\text {th }}$ instar larvae divided into five replicates (ten larvae for each replicate) for both treatment and control. Larval \& pupal durations, pupal weight, adult longevity, fecundity and hatchability percentages were recorded.

\section{Anatomical and histopathological studies:}

Anatomical futures of five ovaries and five testes of S. littoralis were studied at one day after the emergence of virgin moths surviving from larvae treated with sub lethal concentration $\mathrm{LC}_{25}$ of methoxyfenozide. Female and male moths were dissected microscopically in ringer's solution. Also, histological preparations were made of the five ovaries and five testes of normal females and males and those emerging from treated larvae. The routine histological technique was used for comparison.

\section{Biochemical assays:}

One gram from ovaries and testes resulted from 10 treated larvae with $\mathrm{LC}_{25}$ of methoxyfenozide and those of normal were collected after one day of emergence for biochemical assays. Samples were homogenized in distilled water $(50 \mathrm{mg} / \mathrm{ml})$ using chilled glass Teflon homogenizer. Homogenates were centrifuged at $5000 \mathrm{rpm}$ for 20 minutes at $5{ }^{\circ} \mathrm{C}$ in a refrigerated centrifuge. The deposits were discarded and the supernatants were kept in a deep freezer at $-20{ }^{\circ} \mathrm{C}$ till use. Three replicates were used for each assay. 
Total soluble protein:

Colorimetric determination of total soluble protein in the total homogenate of samples was carried out as described by Gornall et al. (1949). The principle of this method is based on that protein in the presence of an alkaline cupric sulphate, produce a violet purple colour, the intensity of which is proportional to their concentration.

Total lipids

The total lipids were estimated according to the method of Schmit (1964) using kits from Diamond Diagnostics.

Acid and alkaline phosphatases:

The activities of acid and alkaline phosphatase were determined using the method of Powell and Smith (1954). In this method, the phenol released by enzymatic hydrolysis of disodium phenolphosphatase reacts with 4aminoantipyrine, and by the addition of potassium ferricyanide, the characteristic brown colour is produced.

\section{Phenol oxidase:}

Phenol oxidase assay was based on the method described by Ishaaya and Casida (1974).

\section{Statistical analysis:}

Using the computed percentage of mortalities versus corresponding concentrations, Probit analysis was adopted according to Finney (1971) using a software computer program $\left(\right.$ Costat $^{\circledR} \quad$ Statistical Table 1. Toxicity data of methoxyfenozide against $4^{\text {th }}$ instar larvae of $S$. littoralis after 72 hr. of treatment.

\begin{tabular}{lcccc}
\hline IGR & LC $_{\mathbf{2 5}} \mathbf{~ p p m}$ (Lower-Upper) & $\mathbf{L C}_{\mathbf{5 0}} \mathbf{~} \mathbf{\text { pm }}$ (Lower-Upper) & $\mathbf{L C}_{\mathbf{9 0}} \mathbf{p p m}$ (Lower-Upper) & Slope \\
\hline Methoxyfenozide & 0.723 & 4.362 & 149.240 & 0.815
\end{tabular}

\section{Larval and pupal duration:}

Data showed prolonged life in both larval and pupal stages (11.45 \pm 0.10 and $10.76 \pm 0.90$ days) as compared to control that recorded $(9.22 \pm 0.66$ and $9.15 \pm 0.68)$ days, respectively. These prolongations are significant $(p<0.05$, L.S. $D_{0.05}=2.18$ ) only in larvae, (Fig. 1 (a)).

\section{Pupal weight:}

Methoxyfenozide caused significant reduction in the resulting pupal weight $(0.3408 \pm 0.01 \mathrm{gm})$ as compared to pupal control $(0.3756 \pm 0.01 \mathrm{gm}),\left(p<0.05\right.$, L.S.D $\mathrm{D}_{0.05}=$ 0.025, Fig. 1 (b)).

\section{Longevity of adults:}

Longevity of female adult that includes preoviposition period, oviposition and post-oviposition periods were shown in (Fig. 1 (c)). Results indicated that, adult females of $S$. littoralis developed from treated larvae recorded highly significant elongation in both pre and postoviposition periods $(4.86 \pm 0.25$ and $3.00 \pm 0.012$ days $)$ comparing to controls $(2.45 \pm 0.22$ and $1.01 \pm 0.15)$, respectively, $\left(p<0.01\right.$, L.S. $\left.\mathrm{D}_{0.05}=0.94\right)$ and $(p<0.01$, L.S. $\left.D_{0.05}=0.54\right)$, while significant reduction in the oviposition period $(3.29 \pm 0.31$ days $)$ was observed as compared to control ( $4.10 \pm 0.35$ days), $\left(p<0.05\right.$, L.S. $D_{0.05}=$ $1.31)$. Generally, the longevity of both treated females and males were significantly increased and recorded (11.15 \pm 0.089 and $11.67 \pm 0.34$ days), control adults lasted (7.56 \pm 0.26 and $7.18 \pm 0.31$ days, respectively), $(p<0.05$, L.S. $\left.D_{0.05}=0.54\right)$ and $\left(p<0.05\right.$, L.S.D $D_{0.05}=1.29$, Fig. 1 c)

\section{Fecundity:}

The number of eggs laid/female moths resulted from larvae fed on leaves treated with $\mathrm{LC}_{25}$ of methoxyfenozide recorded highly significant reduced as compared to control. $\left(p<0.01\right.$, L.S. $\left.D_{0.05}=500.14\right)$. Control gave $2645.50 \pm 100.041$ eggs/female, while treated females laid an average $1642.83 \pm 0.5025$ eggs/female, (Fig. $1 \mathrm{~d}$ ).
Software 2005). This yields the toxicity indices $\left(\mathrm{LC}_{25}\right.$, $\mathrm{LC}_{50}$ and $\left.\mathrm{LC}_{90}\right)$ as well as the related parameters $(95 \%$ confidence intervals, slope, and chi-square, $\chi^{2}$ ) for established toxicity regression lines. biological and biochemical trials were determined by analysis of variance (ANOVA). The significance of various treatments was evaluated by Duncan's multiple range test $(\mathrm{p}<0.05)$ (Snedecor and Cochran 1980). Means were compared using L.S.D. (5\% significance level). Data were subjected to statistical analyses via a software package Costat $^{(B)}$ Statistical Software (2005) a product of Cohort Software, Monterey, California.

\section{Toxicological effects:}

\section{RESULTS}

Data presented in (Table 1) showed the efficiency of the tested IGR (ecdysone agonist) against $4^{\text {th }}$ instar larvae of $S$. littoralis after 72 hours of treatment, values of $\mathrm{LC}_{25}, \mathrm{LC}_{50}$ and $\mathrm{LC}_{90}$ recorded $(0.723,4.362$ and 149.240 ppm, respectively).

\section{Biological parameters:}

Series of biological parameters studies including larvae, pupae and adults which developed from $4^{\text {th }}$ instar larvae of $S$. littoralis treated with sub lethal concentration $\left(\mathrm{LC}_{25}\right)$ of methoxyfenozide were summarized in (Fig. 1).

\section{Hatchability percentages:}

Data demonstrated in (Fig. 1 e) indicated that there was a highly significant reduction in egg hatchability percentages as affected by methoxyfenozide $(62.85 \pm 3.39 \%)$, while control manifested $(94.21 \pm 2.41 \%)$, $\left(p<0.01\right.$, L.S.D $\left.D_{0.05}=15.45\right)$.

\section{Anatomical and histopathological studies}

Adult female moth

Anatomically normal female moth of $S$. littoralis has one pair of ovaries; each consists of four convoluted polytrophic ovarioles united distally by the terminal filament. The ovariole is divided into three regions, terminal filament, the zone of germanium and zone of vitellarium (Fig. 2a, b\& c), while ovaries of virgin moths survived after larval treatment with sub lethal concentration $\mathrm{LC}_{25}$ of methoxyfenozide became relatively smaller in size than the normal one (Fig. 2d).

Histologically each normal ovariole of the vitellogenic stage has a chain of developing eggs in follicles. Each follicle consists of a growing oocyte accompanied interiorly by a few number of nurse cells (trophocytes), the oocyte surrounded by somewhat columnar to cuboidal follicular epithelium (Fig. 3a)

Ovaries of $S$. littoralis adult female resulting from treated larvae with $\mathrm{LC}_{25}$ concentration of methoxyfenozide showed abnormal accumulation of chromatin in nurse cells nucleus and appearance of vacuoles (Fig. $3 b \& c$ ).

In post vitellogenic stage for abnormal ovarioles, there is obvious degeneration of the wall between oocytes followed by a complete separation between oocytes. Decrease and disorganization in the amount of yolk granules leading to warp of egg chorion. (Fig. $4 \mathrm{~b} \&$ c) comparing to normal post vitellogenic stage (Fig. 4a).
The significances of the main differences in 


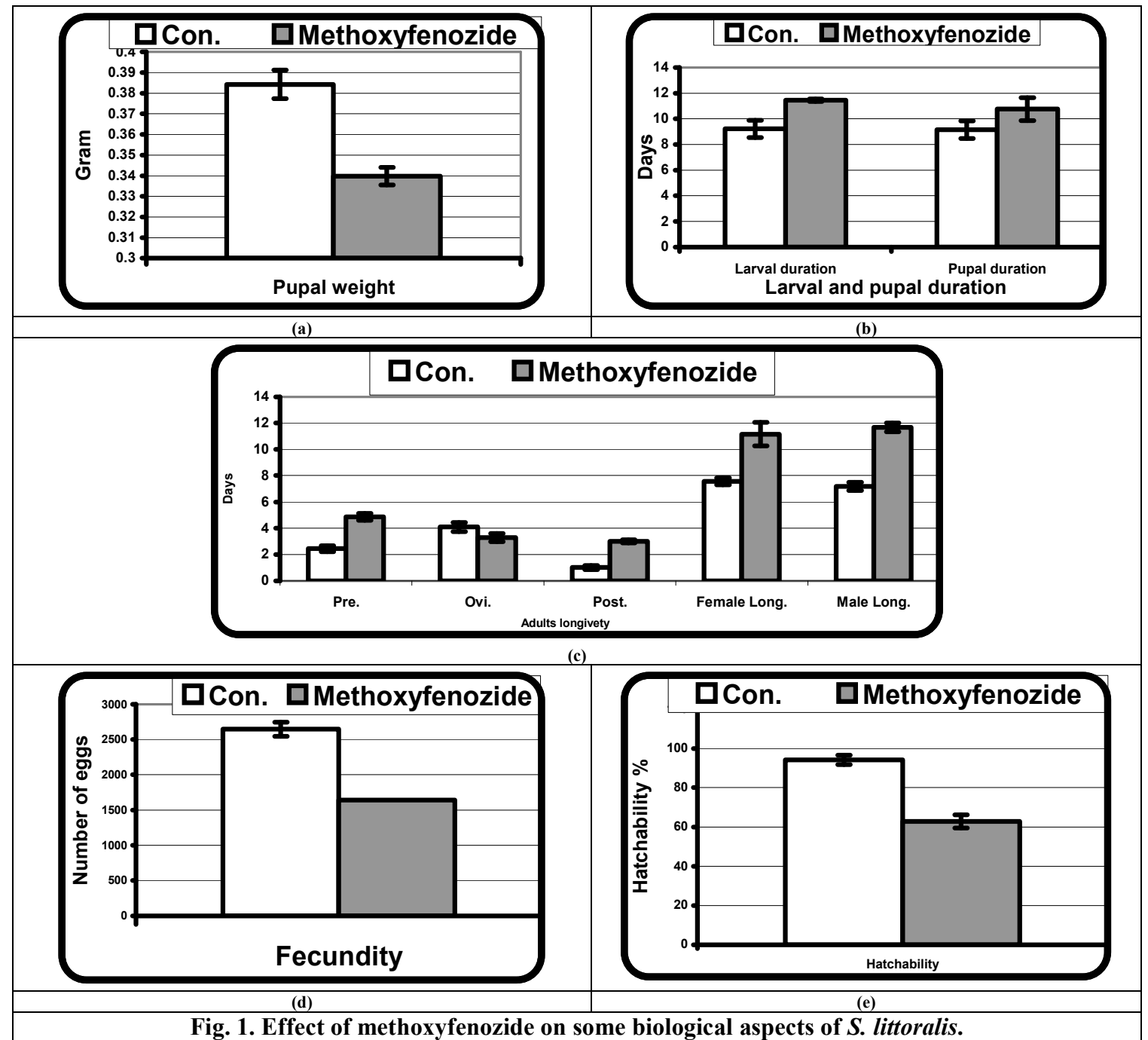

Fig. 1. Effect of methoxyfenozide on some biological aspects of $S$. littoralis.

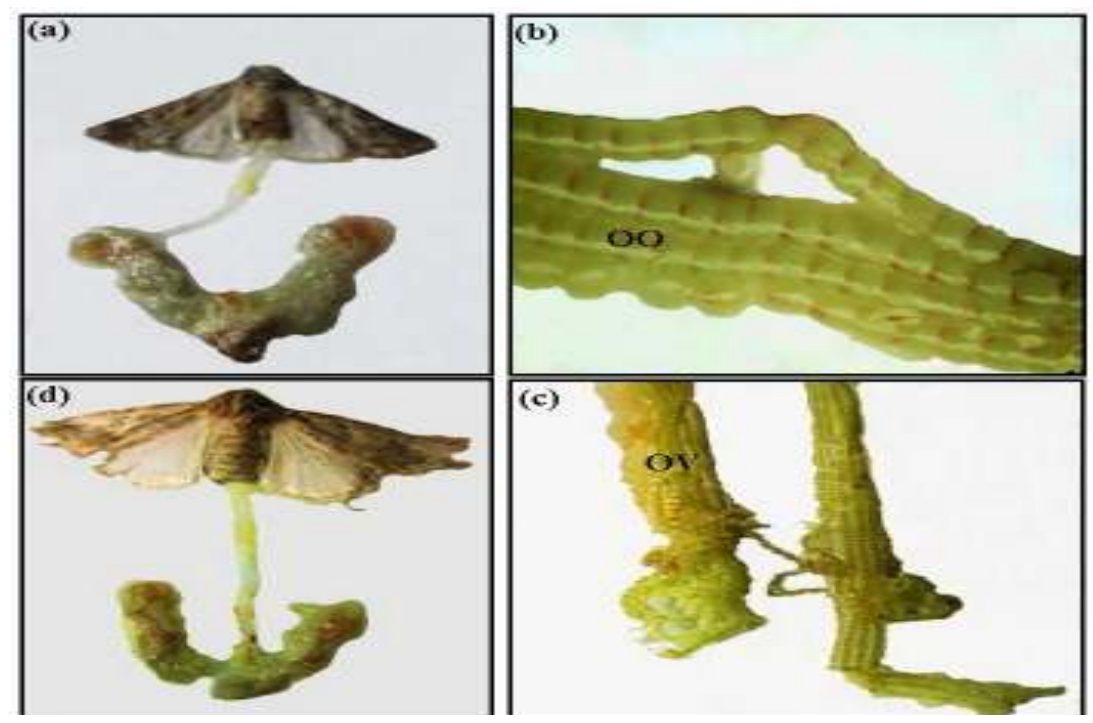

Fig. 2. Ovaries of Spodoptera littoralis showing:

A. Normal shape of ovarioles.

B. \& C. Normal ovaries showing four ovarioles growing oocytes $(\mathrm{OO})$ and $(\mathrm{OV})$ ovariole.

D. Ovaries of female moth survived from treated larvae of $S$. littoralis with methoxyfenozide showing atrophy in size of ovaries and degenerated ovarioles. 

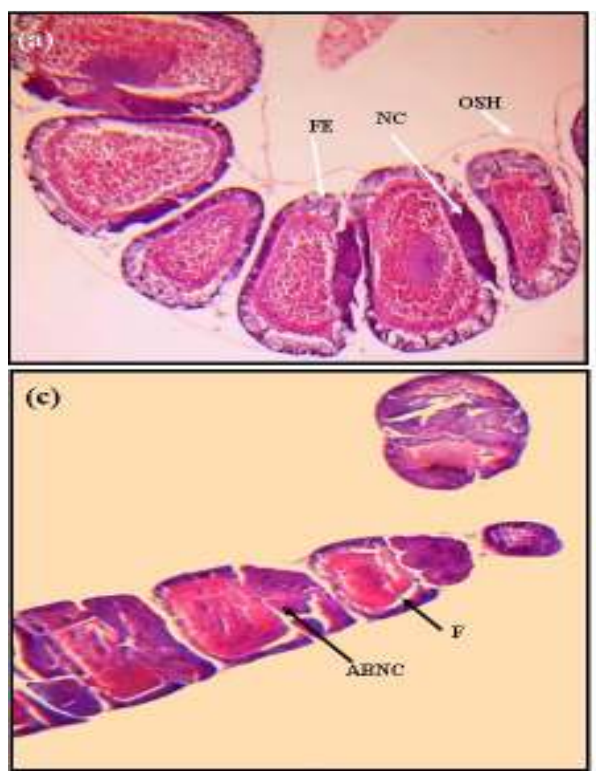

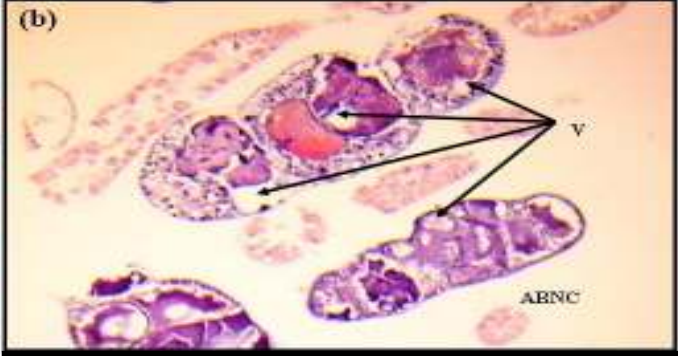

A. Normal nurse cell, follicle cell and follicular epithelium.

B\&C. Ovariole of vitellogenic stage of female $S$. littoralis following treatment with methoxfenozide showing clumping of chromatin of nurse cell and appearance of vacuoles in nurse cells, (ABNC) Abnormal Nurse Cell, (F) Fissure, (FE) follicular epithelium, (NC) nurse cell, (OSH) Oocyte Sheath, (V) Vacuole and (Y) Yolk.

Fig. 3. L.S of ovariole of vitellogenic stage showing

\section{Adult male moth}

Anatomically normal male moth of $S$. littoralis has one pair of testes has pale creamy color and so closely apposed that they appear as a single round organ enclosed in a common membrane. Each testis lead to a vas deferens, which end at seminal vesicles (Fig. 5a). Generally, the testes of male moths resulting from treated larvae with $\mathrm{LC}_{25}$ concentration of methoxyfenozide were smaller in size than the normal. The testicular follicles were also smaller and narrower (Fig. 5b).

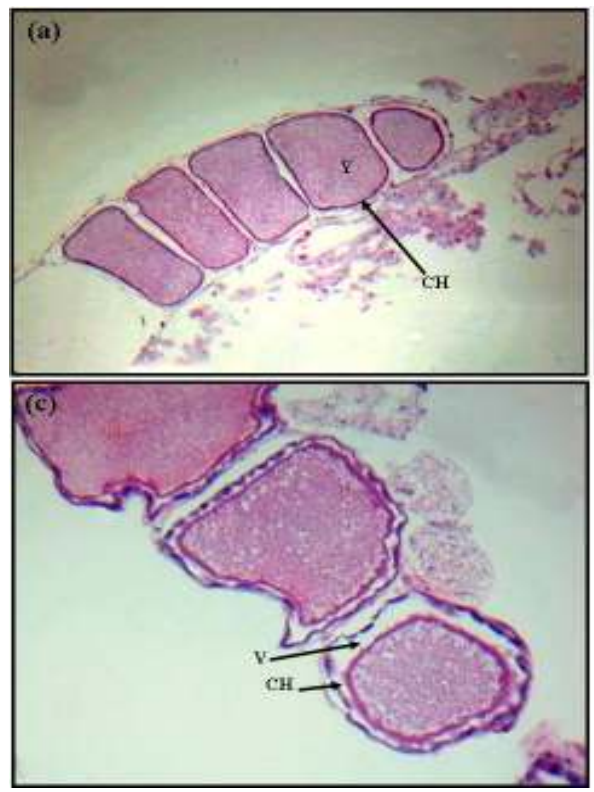

Fig. 4. L. S of ovariole of normal post vitellogenic stage showing
The histological examination of normal testes showed an external wall (testicular wall) which surrounds the germinative cells. The arrangement of the germ cells in the testes shows that this structure is formed by unique and long follicle with several cysts (Fig. 6a). Histological studies of testes from adults derived from treated larvae revealed clear reduction in cellular content and bundles of spermatocytes and spermatogonia were severely reduced in number which delayed spermatogenesis (Fig. $6 \mathrm{~b} \& \mathrm{c}$ )

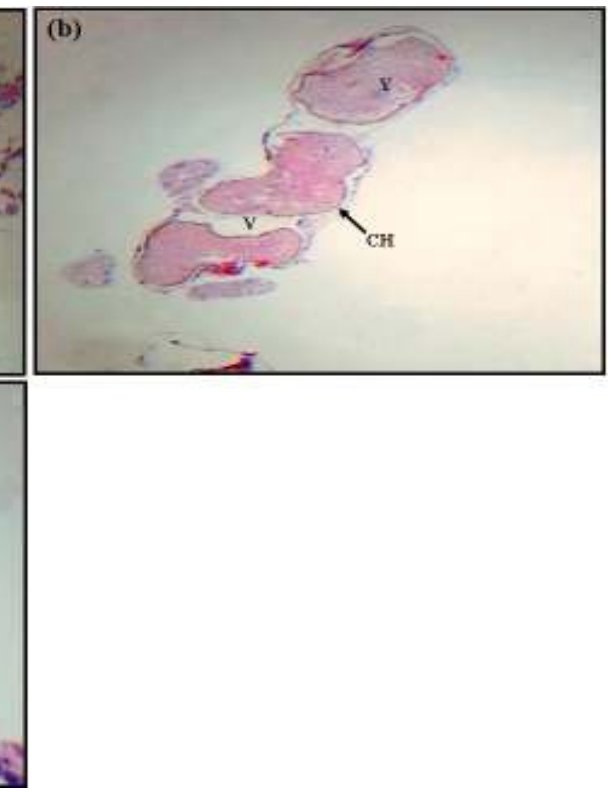



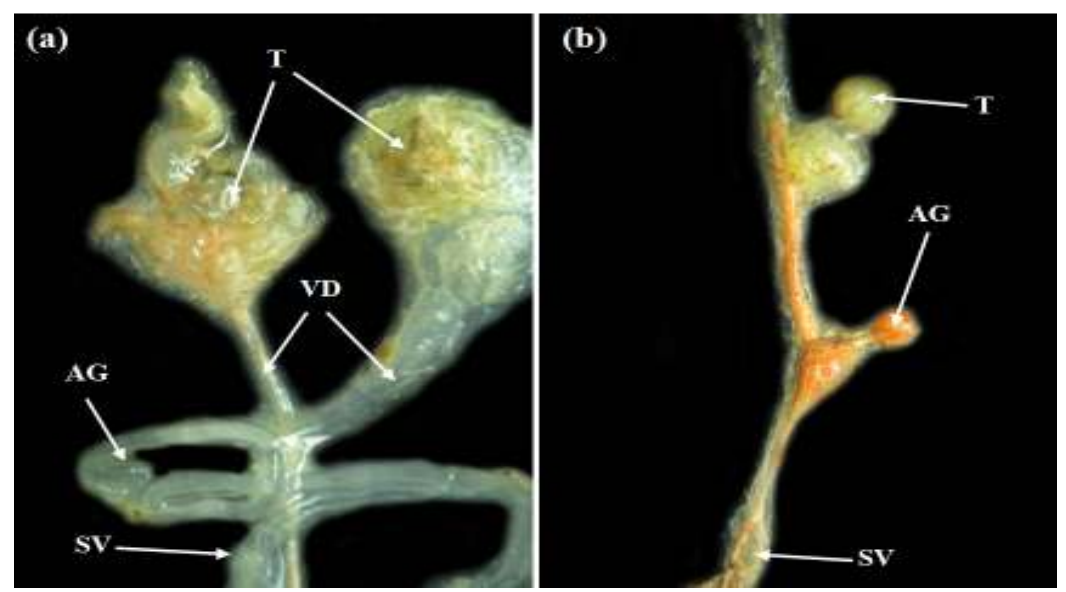

Fig. 5. Photomicrograph of male reproductive system of $S$. litroralis.

(a) Normal male. (b) Treated male. (T) Testes. (VD) Vas Deferens. (AG) Accessory Gland. (SV) Seminal Vesicles.

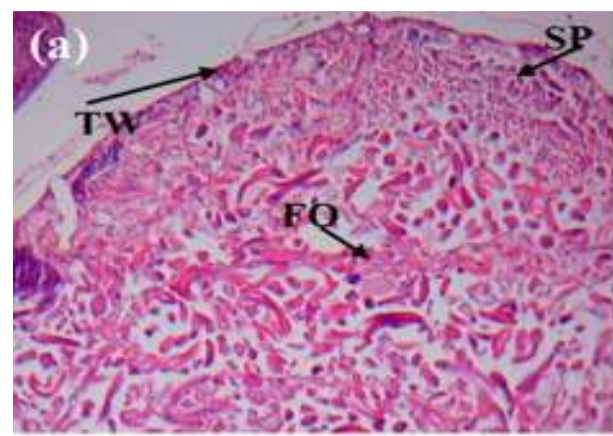

(c)

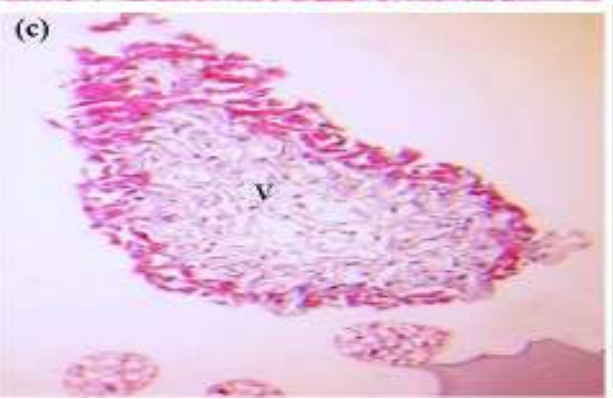

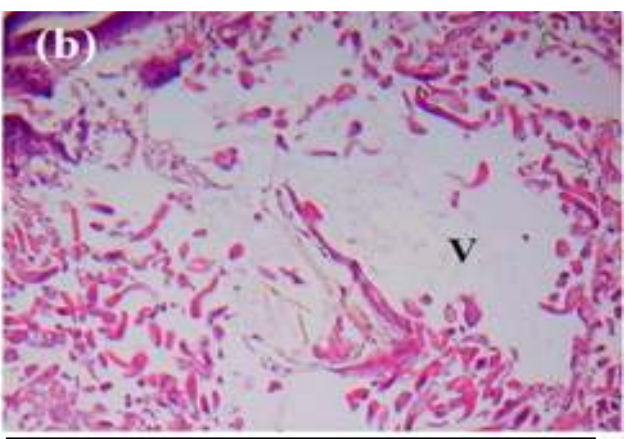

Fig. 6. L.S of testes of $S$. littoralis male, (a normal testes showing testicular wall, follicles and spermatogonia, (b \& c) Abnormal testes showing vacuoles between follicles and degeneration of testicular wall. (FO) Follicle, (SP) Spermatogonia, (TW) Testicular Wall, (V) Vacuole.

\section{Biochemical assays:}

The changes in the amounts of both total soluble protein and total lipids, and activities of Acid and Alkaline phosphatases and phenol oxidase in the supernatant of the homogenated ovaries and testes resulting from $4^{\text {th }}$ instar larvae of $S$. littoralis treated with $\mathrm{LC}_{25}$ of methoxyfenozide were measured after one day of emergence (Fig. 7).

\section{Total soluble protein:}

Generally, methoxyfenozide caused significant reduction in the amount of total soluble protein in both resulting ovaries $(26.15 \pm 2.07 \mathrm{mg} / \mathrm{gm})$ and testes $(16.67 \pm 1.73 \mathrm{mg} / \mathrm{gm})$ as compared to control ovaries $31.60 \pm 3.16 \mathrm{mg} / \mathrm{gm}\left(p<0.05\right.$, L.S.D $\left.\mathrm{D}_{0.05}=4.11\right)$ and control testes $41.61 \pm 3.47 \mathrm{mg} / \mathrm{gm},\left(p<0.05\right.$, L.S.D ${ }_{0.05}=$ 13.32, Fig. 7 a).

Total lipids:
Data in (Fig. $7 \mathrm{~b}$ ) indicate that, the fluctuations in results between highly significant reduction in the amounts of lipids that measured in tested ovaries that recorded $33.59 \pm 4.03 \mathrm{mg} / \mathrm{gm}$ as compared to normal ones 74.71 \pm 3.87 , $\left(p<0.01\right.$, L.S. $\left.\mathrm{D}_{0.05}=15.53\right)$. Whereas, a highly significant increase in tested testes $(29.00 \pm 2.97$ $\mathrm{mg} / \mathrm{gm})$ as compared to normal testes $65.30 \pm 3.19$, ( $p$ $<0.01$, L.S. $\mathrm{D}_{0.05}=18.81$ ).

Acid phosphatase:

The results showed that methoxyfenozide caused an insignificant reduction in the activity of acid phosphatase (ACP) as compared to control, (Fig. 7 c). The ovaries and testes resulted from treated larvae recorded (31.67 \pm 2.91 and $45.78 \pm 2.88 \mu \mathrm{g} / \mathrm{gm} /$ minute, respectively). Normal ovaries and testes gave $(38.21 \pm 2.13$ and $48.83 \pm 2.51)$, $(p>0.05)$. 
Alkaline phosphatase:

Data presented in (Fig. 7d) revealed a highly significant decrease in alkaline phosphatase (ALP) comparing to control. Normal ovaries and testes gave (7.39 \pm 0.47 and $0.66 \pm 0.08 \mu \mathrm{g} / \mathrm{gm} /$ minute, respectively). Opposite to treated ovaries and testes $(3.15 \pm 0.39$ and $0.35 \pm 0.1 \mu \mathrm{g} / \mathrm{gm} / \mathrm{minute}), \mathrm{p}=0.004$ and 0.008 , respectively.

Phenol oxidase:

Regarding phenol oxidase enzyme, there was an insignificant decrease in the activity of the resulting ovaries $(553.50 \pm 45.32 \mu / \mathrm{gm})$ comparing to normal ovaries $555 \pm 60.02 \mu / \mathrm{gm},(P>0.05)$. Whereas, the reduction was highly significant in the resulting testes $(125 \pm 14.10 \mu / \mathrm{gm})$, obverse to control testes $273 \pm 16.68 \mu / \mathrm{gm}, \quad(p<0.01$, L.S.D0.05=64.99, Fig. 7 e).

\section{DISCUSSION}

The toxic effect of methoxyfenozide (ecdysone hormone agonist) against $4^{\text {th }}$ instar larvae of $S$. littoralis under laboratory conditions may be attributed with incomplete and lethal molts of larvae. That is perhaps due to the disturbance in the normal hormone balance leading to a crucial disorder in the development and growth of insects and subsequently larval mortality. The same conclusion was obtained by Dhadialla et al. (2005) when tested tebufenozide (ecdysone agonist) against Lepidoptera. In addition, Khedr (2011) found that methoxyfenozide has larvicidal activity against both $2^{\text {nd }}$ and $4^{\text {th }}$ instars of $S$. littoralis larvae under laboratory conditions, he added that after $72 \mathrm{hr}$ of treatment, larvae had problems in discarding the old cuticle, precocious molt led to the production of larvae with abnormal chitin deposition. Based on the above, the mortality of larvae probably due to the disturbance in larval bioassay after ingestion the leaves treated with methoxyfenozide.

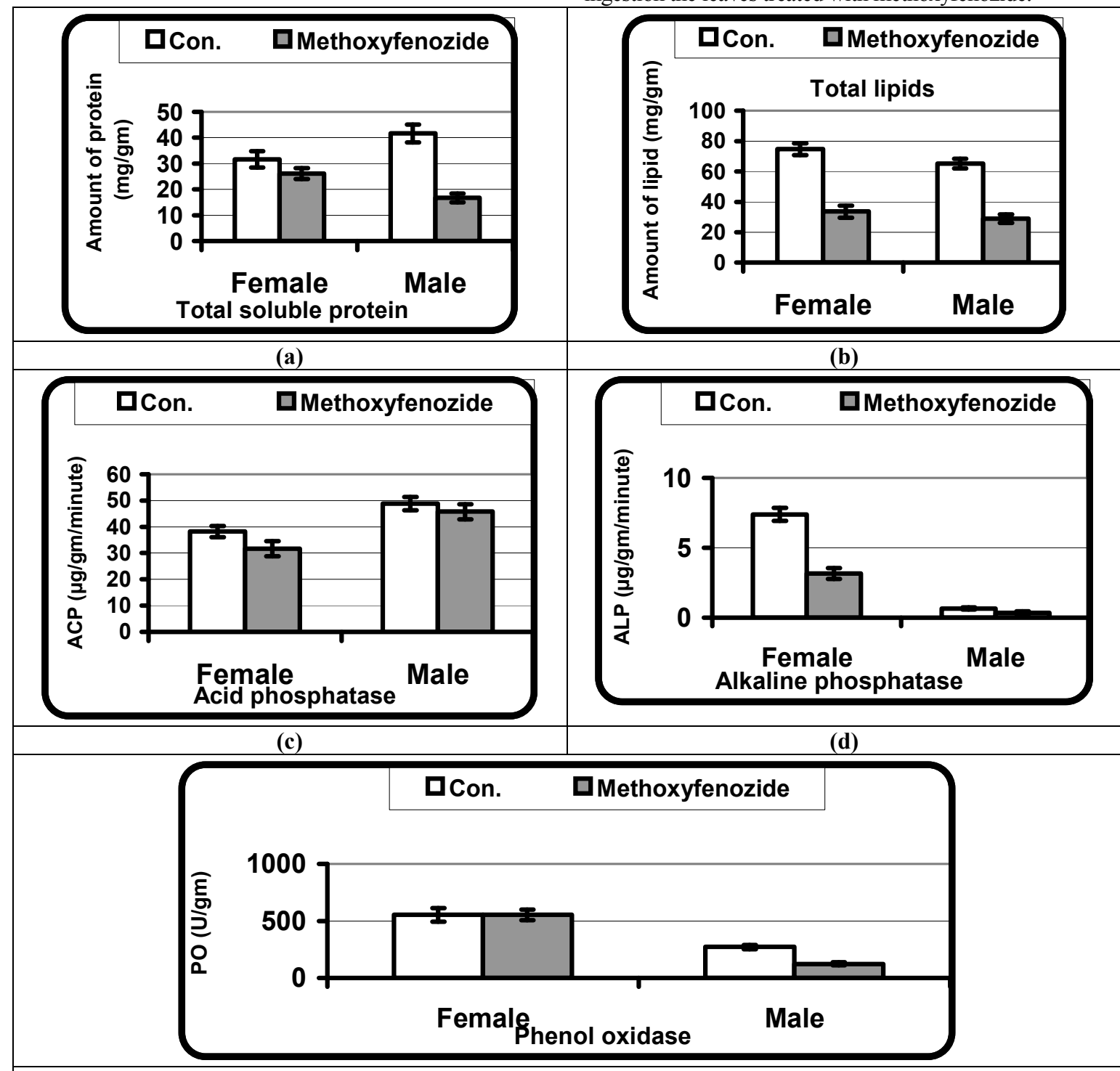

(e)

Fig. 7. Changes in the levels of measured biochemical parameters in the homogenated ovaries and testes of $S$. littoralis adults treated with methoxyfenozide. 
Histopathological effects on ovaries of $S$. littoralis females resulted from larvae treated with LC25 of methoxyfenozide showed vacuolation in the cytoplasm of the nurse cells and follicular epithelium and clumping of the chromatin material. This treatment may be affecting the plasma membrane osmotic properties, leading to dehydration and appearance of vacuoles within the oocytes, shrinkage or degeneration of the yolk and warping of egg chorion vacuolation in the cytoplasm of the nurse cells.

These histological alterations are similar to those found on Ephestia kuehniella ovaries treated with methoxyfenozide (Bakli et al., 2016), or on S. littoralis ovaries as affected by pyriproxyfen and Schinus terebinthifolius extract (Shaurub et al., 1998). Moreover, Abdel-Aal (2012) reported the same effects in ovaries after treatment of fourth larval instar of $S$. littoralis with chlorofluazuron. While, Shaurub et al., (1999) observed completely damage of Agrotis ipsilon ovaries treated as larvae with chlorfluazuron.

Histopathological effects on testes of S. littoralis male survived after larval treatment with LC25 of methoxyfenozide had narrower follicles and the follicles showed disorganization and vacuolations between them. The spermatogonia and spermatocytes were reduced in number. These observed results are in agreement with the studies on other insect species, (Wilson and Hays 1969) on houseflies following treatment with certain chemosterilants. Also, El-Bokl et al., (2010) demonstrate the same effect on Rhynchophorus ferrugineus treated with Neem and flufenoxuron. Additionally, Bouzeraa \& Soltani-Mazouni (2014) found that IGRs (Tebufenozide and methoxyfenozide) affect the morphometry of Ephestia kuehniella testes

Significant depletion of total soluble protein was detected in both ovaries and testes of S. littoralis adults as compared to control. Protein and lipids are known as nutritional indices in insects. Proteins are the major components in both hormones and enzymes. Lipids are fundamental in synthesizing the phospholipids which are very important components in many hormones, cell membrane and provide the insect with its energy requirements.

Proteins can bind or interfere with the foreign compounds and subsequently the reduction in proteins may reflect the inhibition of the detoxifying enzyme activities (Wilkinson 1976). Additionally, protein depletion in the tissue of both ovaries and testes may be due to the breakdown of proteins and conversion to amino acids under insecticidal stress (Nath et al., 1997). The fluctuation between the highly significant decrease in the amounts of lipids in ovaries and highly significant elevation in testes comparing to its controls were recorded in this study as affected by methoxyfenozide. Similar difference in the amount of lipids was observed by Etebari et al., (2007) when tested pyriproxyfen in the haemolymph of silkworm. The possible mechanisms of these difference were explained by Zera and Zhao (2004) when found juvenile hormone analogs decrease activities of total lipids, lipogenic enzymes and triglyceride lipid biosynthesis, on contrary, they elevate the oxidation of fatty acids and biosynthesis of phospholipids.
Methoxyfenozide caused an insignificant decrease in the activity of acid phosphatase (ACP) and a significant reduction in the activity of alkaline phosphatase (ALP) in both ovaries and testes of $S$. littoralis adults as compared to adult controls. ACP is more critical than ALP in some physiological processes in the reproductive organs of adults, which may be due to the $\mathrm{pH}$ value of these organs. ACP and ALP play role in the final steps of lipid digestion in insects (Klowden 2013). Therefore, the changes in the activity of these enzymes may be affecting the physiological process that depends on the digestion and positive transportation of nutrients (Etebari et al., 2007).

In this paper, the histochemical studies attempted to reply some inquires occurred in the precedent biological parameters that induced the effect on pupae and adults developed from S. littoralis larvae poisoned with sub lethal concentration (LC25) of methoxyfenozide on the resulting reproductive organs (testes and ovaries).

S. littoralis had significantly prolonged life in both larval and adults (male \& female) stages, while insignificant in pupal stage. Theses prolongation may be due to that methoxyfenozide caused disturbance in the normal hormone balance which causes a crucial disorder in growth and development. Sabry and Khedr (2014) observed abnormalities in the shape of epicuticle, endocuticular deposition and abortive molting after treating $S$. littoralis 4th instar larvae with methoxyfenozide. Also, Hamaidia and Soltani (2016) found that the duration of total immature development of Culex pipines was significantly prolonged by methoxyfenozide. Pupal weight was also significantly reduced as compared to pupal control. That is may be attributed with an abnormality in larval development and subsequently lower efficiency conversion of food. The same conclusion obtained by (Smagghe et al., 2012) when tested methoxyfenozide against larvae of Lymantria dispar. In our study, data showed that the subsequent parameters in adults resulting from larvae exposed to LC25 of methoxyfenozide expressed as significantly elevation in both pre and post oviposition periods, significantly reduce in the oviposition periods, fecundity and hatchability percentages comparing to those of resulting adult controls. Histological and biochemical variations in the reproductive organs (ovaries and testes) may be the key factor to influence the ovicidal action of methoxyfenozide. Results clearly describe the significant discrepancies in the amount of total soluble protein and total lipids in the resulting treated ovaries, additionally decrease activities of ACP, ALP and PO which are very important in development and interfere with the physiological process, suggesting abnormalities in the development of ovaries, thus reduce fecundity as compared to normal ovaries. Mead et al., (2016) recorded that disruption in ACP and ALP enzyme activities and total soluble protein ultimately lead to abnormal S. littoralis eggs.

Moreover, the histological alterations in the abnormal ovaries suggested that methoxyfenozide arrest ovarian development which perhaps delaying the transition from vitellogenesis to choriogenesis. The same result was obtained by methoxyfenozide on other lepidopteran species including Cydia pomonella and Bombyx mori (Sun et al., 2003; Swevers and Iatrou 2003). Therefore, the 
elongation in the pre-oviposition period and decrease the timing of the oviposition period were observed in the surviving female control. Additionally, the decrease in the amount of yolk granules leading to wrap of egg chorion that is probably resulting defective eggs which losing its viability as compared to normal ones. Smagghe et al., (1996) suggested that ecdysone agonist (Methoxyfenozide) might arrest the ovarian growth of Cydia pomenella or block sperm transfer to females, that is because oogensis and vitellogenesis already started at the late of pupal stage or onset adult stage (Webb et al., 1999). Similarly, the results presented here in provide evidence that methoxyfenozide affect the mating ability of male surviving from treated larvae either decrease the size of testes than normal testes or delaying spermatogenesis, as well as reduce the number of spermatocytes and spermatogonia. Furthermore, methoxyfenozide impact upon the precedent biochemical assays in the male testes either decrease or increase as compared to normal male testes. These findings may be explaining the reason in the reduction of hatchability percentages comparing to control. Seth et al., (2004); and Shahout et al., (2011) found a reduction in fecundity, sperm production and sperm transfer resulting from $S$. littoralis larvae exposure to sublethal concentrations of methoxyfenozide and tebufenozide.

\section{CONCLUSION}

The ecdysteroid agonist (methoxyfenozide) exhibited delayed effects on growth and development of $S$. littoralis stages. Furthermore, several aberrations in the reproductive organs either ovaries or testes were observed. Thus, methoxyfenozide possess remarkable larvicidal and ovicidal activities. These findings are important and useful to incorporate methoxyfenozide into IPM programs for control S. littoralis.

\section{REFERENCES}

Abbott, W. S. (1925). A method of computing the effectiveness of an insecticide. Journal of Economic Entomology. 18: 265-267.

Abdel-Aal, A. E. (2012). Effect of three insect growth regulators (Chlorfluazuron, Tebufenozoide and pyriproxyfen) on fecundity of Spodoptera littoralis, histopathological and some biochemical aspects of moth ovary. Egyptian Academic Journal of Biological Sciences. 4: 49- 59.

Al-Shannaf, H. M. H. and M. M. A. Khedr (2013). Bioefficiency of some biorational compounds against Spodoptera littoralis (Boisd.) under laboratory and field conditions. Bulletin of Entomological Society of Egypt, Economic Series. 39: 111-129.

Bakli, D.; Kirane-Amrani, L.; Soltani-Mazouni N. and N. Soltani (2016). Methoxyfenozide, an ecdysteroid agonist insecticide, alters oocyte growth during metamorphosis of Ephestia kuehniella Zeller. African Entomology. 24: 453-459.

Bellés, X. (2005). Vitellogenesis directed by juvenile hormone. p. 157-197. In: Raikhel, A. S. (Ed.) Reproduction biology of invertebrates, Vol. 12, Part B: Progress in Vitellogenesis. Science Publishers Inc., Enfield, USA., and Plymounth, UK. 426 p.
Bouzeraa, H. and N. Soltani-Mazouni (2014). Comparative effects of two moulting hormone agonists (methoxyfenozide and tebufenozide) on the Mediterranean flour moth Ephestia kuehniella Zeller (Lepidoptera: Pyralidae): Ecdysteroids amounts of testes and reproductive events. World Applied Sciences Journal. 31: 1903-1910.

Costat Statistical Software (2005). Microcomputer program analysis version, 6. 311. CoHort Software, Monterey, California, U S A.

Dhadialla, T. S.; Retnakaran, A. and G. Smagghe (2005). Insect growth and development disrupting insecticides. In: Gilbert L.I., Costas I., Gill S. (Eds.) Comprehensive insect molecular science Vol. 6. Elsevier, Oxford, UK, pp. 55-116.

El-Bokl, M. M.; Baker, R. F. A.; El-Gammal, H. L. and M. Z. Mahmoud (2010). Biological and histopathological effects of some insecticidal agents against red palm weevil Rhynchophorus ferrugineus. Egyptian Academic Journal of Biological Sciences. 1: 7-22.

El-Defrawi, M. E.; Toppozada, A.; Mansour, N. and M. Zeid (1964). Toxicological studies on the Egyptian cotton leafworm, Prodenia litura. I. susceptibility of different larval instars of Prodenia to insecticides. Journal of Economic Entomology. 57(4): 591-593.

Etebari, K.; Bizhannia, A. R.; Sorati, R. and L. Matindoost (2007). Biochemical changes in haemolymph of silkworm larvae due to pyriproxyfen residue. Pesticide Biochemistry and Physiology. 88: 14-19.

Finney, D. J. (1971). Probit Analysis, a statistical treatment of the sigmoid response curve. 7th Ed., Cambridge Univ Press, Cambridge, England. 333 p.

Gornall, A. G.; Bardawil, C. D. and M. M. David (1949). Determination of serum protein by means of bruit reduction. Journal of Biochemistry. 177: 751-766.

Hamaidia, K. and N. Soltani (2016). Ovicidal activity of an insect growth disruptor (methoxyfenozide) against Culex pipiens L. and delayed effect on development. Journal of Entomology and Zoology Studies. 4: 1202-1207.

Ishaaya, I. and J. E. Casida (1974). Dietary TH 6040 alters composition and enzyme activity of housefly larval cuticle. Pesticide Biochemistry and Physiology. 4: 484-490.

Khedr, M. M. A. (2011). Efficiency of some alternative compounds in controlling cotton leafworm, Spodoptera littoralis (Boisd.). [Ph. D. Thesis]. Egypt. Faculty of Agriculture, Banha Univiversity. $214 \mathrm{p}$.

Klowden, M. J. (2013). Physiological systems in insects. Academic Press. 681 p.

Mead, H. M.; El-Shafiey, S. N. and H. M. Sabry (2016). Chemical constituents and ovicidal effects of mahlab, Prunus mahaleb L. kernels oil on cotton leafworm, Spodoptera littoralis (Boisd.) eggs. Journal of Plant Protection Research. 56: 279-290.

Nath, B. S.; Suresh, A.; Varma, B. M. and R S. Kumar (1997). Changes in protein metabolism in hemolymph and fat body of the silkworm, Bombyx mori (Lepidoptera: Bombycidae) in response to organophosphorus insecticides toxicity. Ecotoxicology and Environmental Safety. 36: 169173. 
Powell, M. E. A. and M. J. H. Smith (1954). The determination of serum acid and alkaline phosphatase activity with 4-aminoantipyrine (AAP). Journal of Clinical Pathology. 7: 245-248.

Raikhel, A. S.; Brown, M. R. and X. Bellés (2005). Hormonal control of reproductive processes. In: Gilbert L.I., Iatrou K., Gill, S.S. (Eds) Comprehensive molecular insect science, Vol.3: Endocrinology. 433-491. Elsevier, San Diego, CA, USA.

Rehan, A. and S. Freed (2014). Resistance, selection, mechanism and stability of Spodoptera litura (Lepidoptera: Noctuidae) to methoxyfenozide. Pesticide Biochemistry and Physiology. 110: 7-12.

Sabry, H. M. and M. A. Khedr (2014). Biochemical and histological variations induced by IGRs in Spodoptera littoralis (Boisd.). Global Journal of Environmental Science and Toxicology. 1: $163-$ 178.

Schmit, J. M. (1964). Colorimetric determination of serum total lipids using sulfophosphovanilic mixture. Ph.D. thesis, Lyon. Biomerieurx Company of France.

Seth, R. K.; Kaur, J. J.; Rao, D. K. and S. E. Reynolds (2004). Effects of larval exposure to sublethal concentrations of the ecdysteroid agonists $\mathrm{RH}$ 5849 and tebufenozide (RH-5992) on male reproductive physiology in Spodoptera litura. Journal of Insect Physiology. 50: 505-517.

Shahout, H. A.; Xu, J-X.; Qiao, J. and Q-D. Jia (2011). Sublethal effects of methoxyfenozide, in comparison to chlorfluazuron and betacypermethrin, on the reproductive characteristics of common cutworm, Spodoptera litura (Fabricius) (Lepidoptera: Noctuidae). Journal of The Entomological Research Society. 13: 53-63.

Shaurub, E. S.; Ahmed Z. A. and S. E. M. El-Naggar (1998). Impacts of pyriproxyfen and extract of Schinus terebinthifolius Raddi on development, reproduction and reproductive organs in Spodoptera littoralis (Boisd.) (Lepidoptera: Noctuidae). Journal of Egyptian German Society of Zoology. 27, 57- 82.

Shaurub, E. H.; Emara, S. A.; Zohdy, N. Z. and A. E. Abdel-Aal (1999). Effect of four insect growth regulators on the black cutworm, Agrotis ipsilon (Hufn.) (Lepidoptera: Noctuidae). The 2nd International Conference of Pest Control, Mansoura, Egypt. 773-776.
Smagghe, G.; Gomez, L. E. and T. S. Dhadialla (2012). Bisacylhydrazine insecticides for selective pest control. p. 163-249. In: "Advances in insect physiology, insect growth disruptors" (Dhadialla T. S. ed.). Elsevier Academic Press San Diego, USA. 43, $531 \mathrm{p}$.

Smagghe, G.; Salem H.; Tirry, L. and D. Degheele (1996). Action of a novel insect growth regulator tebufenozide against different developmental stages of four stored product insects. Parasitica. 52, 61-69.

Snedecor, G. W and W. G. Cochran (1980). Statistical methods $7^{\text {th }}$ Ed. Iowa State University Press. Ames, Iowa, USA. 507 p.

Sun, X.; Song, Q. and B. Barrett (2003). Effect of ecdysone agonists on vitellogenesis and the expression of EcR and USP in codling moth (Cydia pomonella). Archives of Insect Biochemistry and Physiology. 52: 115-129.

Swevers, L. and K. Iatrou (2003). The ecdysone regulatory cascade and ovarian development in lepidopteran insects: insights from the silk moth paradigm. Insect Biochemistry and Molecular Biology. 33: 1285-1297.

Webb, T. J.; Shu, S. Q.; Ramaswamy, S. B. and S. Dorn (1999). Influence of juvenile hormone and mating on oogenesis and oviposition in the codling moth, Cydia pomonalla. Archives of Insect Biochemistry and Physiology. 41: 186-200.

Wilkinson, C. F. (1976). Insecticide biochemistry and physiology. Plenum Press, New York, USA. 768 p.

Wilson, J. A and S. B. Hays (1969). Histological changes in the gonads and reproductive behavior of house flies following treatment with chemosterilants $p$, $p$ Bis (1-aziridinyl)- $N$-methylphosphinic Amide and $\mathrm{p}$, p-Bis (1-aziridinyl)-N-(3-methoxypropyl) phosphinothioic Amide. Journal of Economic Entomology. 62: 690-692.

Zera, A. J. and Z. Zhao (2004). Effect of a juvenile hormone analogue on lipid metabolism in a wingpolymorphic cricket: implications for the endocrine-biochemical bases of life-history tradeoffs. Physiological and Biochemical Zoology. 77: 255-266.

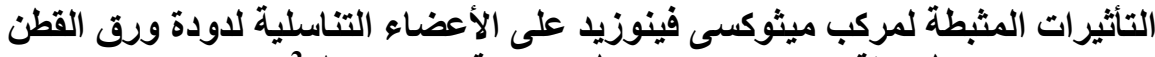

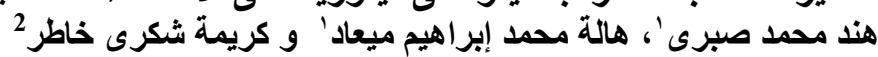

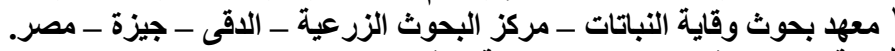

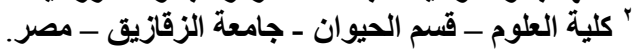

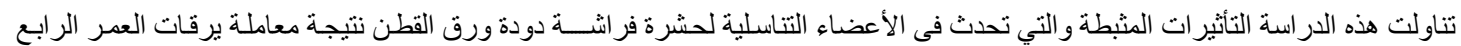

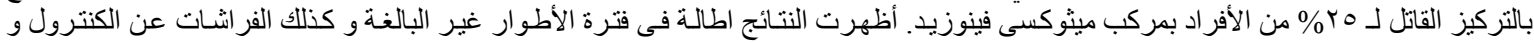

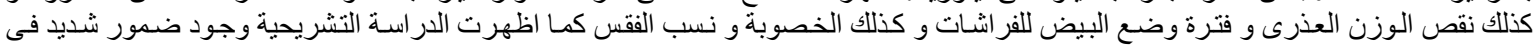

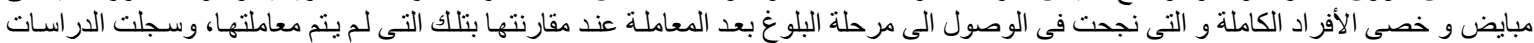

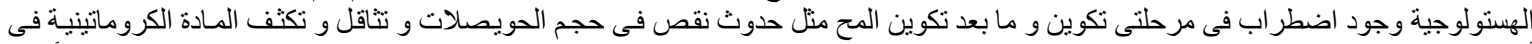

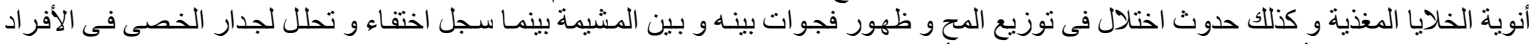

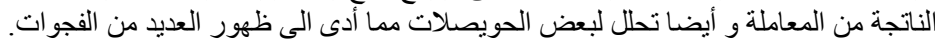

